\title{
OKSIDATIVNA DEGRADACIJA ŽUTE FLEKSO GRAFIČKE BOJE PRIMENOM GVOŽĐE(II)-SULFATA
}

\section{OXIDATIVE DEGRADATION OF YELLOW FLEXO PRINTING DYE USING IRON(II)-SULFATE}

\begin{abstract}
Katarina Novaković, Vesna Gvoić, Miljan Oblast - GRAFIČKO INŽENJERSTVO I DIZAJN

Kratak sadržaj - Predmet istraživanja ovog rada obuhvata tretman otpadne vode obojene žutom bojom $i$ generisane nakon procesa flekso štampe, primenom homogenog Fenton procesa. Uticaj procesnih parametara na efikasnost obezbojavanja sintetičkog rastvora žute boje $i$ realnog efluenta, kao $i$ optimizacija procesa izvršeni su primenom statističke analize: definitive screening design. Fizičko-hemijska karakterizacija efluenta pre $i$ nakon Fenton tretmana je obuhvatila merenje pH vrednosti, električne provodljivosti, temperature $i$ mutnoće. Ispitivanje efikasnosti obezbojavanja vodenog rastvora grafičke boje vršeno je serijom eksperimenata na aparaturi za JAR test.
\end{abstract}

Ključne reči: flekso grafička boja, oksidativna degradacija, Fenton proces, tretman otpadnih voda

\begin{abstract}
The subject of the paper covers the treatment of yellow dyed wastewater generated after flexo printing process by using a homogeneous Fenton process. The influence of the process parameters on the decolorization efficiency of the synthetic yellow solution and the real printing effluent, as well as the process optimization, were performed using the statistical analysis: definitive screening design. The physico-chemical characterization of the effluent before and after Fenton treatment included the measurement of $\mathrm{pH}$, electrical conductivity, temperature and turbidity. Decolorization efficiency of an aqueous solution of printing dye was performed by a series of experiments on a JAR test.
\end{abstract}

Keywords: flexo printing dye, oxidative degradation, Fenton process, wastewater treatment

\section{UVOD}

Iz godine u godinu, grafička industrija beleži tendeciju rasta zbog čega se javlja potreba za novim tehnologijama u ovoj oblasti. Ispuštanje toksičnih derivata u recipijente kao što su teški metali, aromatična jedinjenja i sintetičke boje dovodi do kontaminacije vode i predstavlja ozbiljan ekološki problem.

Različite tradicionalne tehnike se primenjuju u tretmanu industrijskih otpadnih voda koje sadrže boje, kao što su koagulacija/flokulacija, uklanjanje membranama (ultrafil-

\section{NAPOMENA:}

Ovaj rad proistekao je iz master rada čiji mentor je bila dr Miljana Prica, vanr. prof. tracija, reversna osmoza) ili adsorpcija na aktivnom uglju [1]. Tehnike koje se najčešće koriste u unapređenim oksidacionim procesima su: procesi zasnovani na primeni vodonik-peroksida $\left(\mathrm{H}_{2} \mathrm{O}_{2}+\mathrm{UV}\right.$, Fenton i foto-Fenton), fotokatalizi $\left(\mathrm{UV}+\mathrm{TiO}_{2}\right)$, ozonu $\left(\mathrm{O}_{3}, \mathrm{O}_{3}+\mathrm{UV}\right.$ i $\mathrm{O}_{3}+$ katalizator), različitim kombinacijama oksidativnih vrsta, sonolizi, elektrolizi i električnom pražnjenju. Unapređeni procesi oksidacije (eng. Advanced Oxidation Processes AOPs) predstavljaju jednu od potencijalnih tehnologija za uklanjanje različitih kontaminanata vodenih ekosistema. Fenton proces je vrlo efikasan $\mathrm{u}$ degradaciji različitih vrsta boja [2]. Predmet istraživanja ovog rada zahvata područje iz oblasti flekso štampe u cilju tretmana žute flekso grafičke boje primenom gvožđe(II)-sulfata. Ujedno je ispitan uticaj pojedinih procesnih parametara na efikasnost primenjenog homogenog Fenton procesa.

\section{MATERIJALI I HEMIKALIJE}

Eksperiment je rađen na uzorku obojene otpadne vode iz jedne flekso štamparije u Novom Sadu. Uzorak otpadne vode obojen je žutom bojom koja se javlja kao rezultat pranja sistema za boju, raster valjka i valjaka za nanos boje. Tečni otpad iz flekso štamparije se ne skuplja i ne odlaže, već se ispušta u recipijent i samim tim se zagađuje životna sredina. Eksperiment je vršen u cilju ispitivanja mogućnosti obezbojavanja sintetičkog rastvora obojenog žutom flekso grafičkom bojom primenom homogenog Fenton procesa, u cilju optimizacije procesa i primene istog u tretmanu realnog efluenta.

Analiza uzorka otpadne vode vršena je bez njenog prethodnog tretmana. Korišćene su sledeće hemikalije: vodonik-peroksid (30\%, NRK Inženjering, Srbija), natrijum-hidroksid i gvožđe (II)-sulfat heptahidrat (>98,8\% POCH, Poljska), kao i sumporna kiselina (>96\%, J.T. Baker - Fischer Scientific, USA). Odabrana grafička boja za ovaj eksperiment spada u azo boje i proizvedena je od strane Flint grupe. Strukturna formula i osnovne karakteristike grafičke boje su prikazane na sl. 1.<smiles>CC(=O)C(/N=N/c1ccc([N+](=O)[O-])cc1)C(=O)Nc1ccccc1</smiles>

Slika 1. Strukturna formula žute boje 
Primenom metode kalibracione krive (slika 2) ustanovljena je koncentracija žute boje u uzorku otpadne vode koja iznosi 125,82 mg/l.

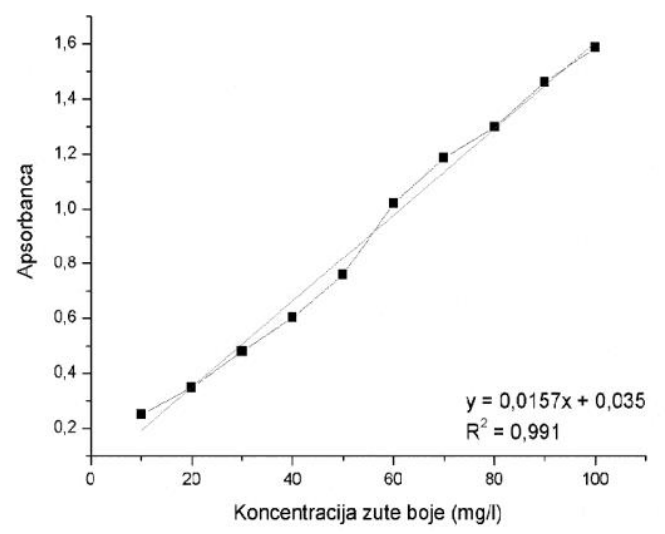

Slika 2. Kalibraciona kriva žute boje

Apsorbanca rastvora grafičke boje je utvrđena na maksimalnoj talasnoj dužini od $437 \mathrm{~nm}$ i izmerena na UV/VIS spektrofotometru (Genesys 10S, Thermo Fisher).

\section{EKSPERIMENT}

\subsection{Eksperimentalna procedura}

Ispitivanje efikasnosti obezbojavanja vodenog rastvora žute grafičke boje vršeno je serijom eksperimenata na aparaturi za JAR test (FC6S Velp scientific, Italija).

U njima je izvršeno mešanje 0,251 vodenog rastvora grafičke boje koncentracije 20-180 mg/l sa Fenton katalizatorom (koncentracija gvožđa 0,75 - 60 mg/l). Nakon podešavanja $\mathrm{pH}$ vrednosti (AD110 Adwa), dodatkom 0,1 $\mathrm{M}$ rastvora $\mathrm{ccH}_{2} \mathrm{SO}_{4}$ ili $\mathrm{NaOH}$, uzorci su mešani u vremenskom periodu od 180 minuta, sa brzinom mešanja $120 \mathrm{o} / \mathrm{min}$ i konstantnom temperaturom od 23 ${ }^{\circ} \mathrm{C}$. Nakon isteka vremena reakcije izmerena je apsorbanca na talasnoj dužini od $437 \mathrm{~nm}$ [3]. Sva merenja vršena su na UV/VIS spektrofotometru Genesys 10S, Thermo Fisher.

Efikasnost obezbojavanja vodenog rastvora grafičke boje i realnog efluenta izračunata je prema jednačini (1):

$$
\mathrm{E}(\%)=\left(\mathrm{A}_{0}-\mathrm{A}\right) / \mathrm{A}_{0} * 100
$$

gde je: $A_{0}$ - početna apsorbanca vodenog rastvora uzorka pre sprovedenog tretmana, a A - apsorbanca vodenog rastvora uzorka nakon sprovedenog tretmana.

\subsection{Dizajn eksperimenta}

Efikasnost primenjenog tretmana zavisi od više procesnih parametara, što iziskuje i optimizaciju celokupnog procesa. Zbog problema koji nastaje primenom više varijabli uključenih u eksperimentalni dizajn, neophodno je koristiti metode statičkog skrininga koji će detektovati značajne i eliministati nepotrebne varijable. U tu svrhu je moguće koristiti skup empirijskih statističkih metoda koje se baziraju na primeni kvantitativnih podataka odgovarajuće osmišljenih eksperimenata sa ciljem određivanja optimalnih uslova [4].

U ovom radu korišćena je statistička analiza definitive screening design (DSD) kako bi se ispitao uticaj četiri procesna parametra: početne koncentracije boje (20 - 180 $\mathrm{mg} / \mathrm{l})$, koncentracije gvožđa kao katalizatora u heterogenom Fenton procesu $(0,75$ - $60 \mathrm{mg} / \mathrm{l}), \mathrm{pH}$ vrednosti $(2$ - 10) i koncentracije vodonik-peroksida (1 $11 \mathrm{~mm})$.

Godine 2011. od strane Jones i Nachtsheim uvedena je DSD analiza, koja omogućava da se sa manjim brojem eksperimenata obezbedi dovoljan broj stepeni slobode koji će omogućiti modeliranje svih potrebnih varijabli u posmatranom procesu. Svi eksperimenti su rađeni $u$ duplikatu sa dodatkom još dve centralne tačke. Za četiri numerička faktora, korišćeni softver za statističku analizu podataka u ovoj studiji, JMP 13, generisao je tabelu sa 15 eksperimenata (tabela 1).

Tabela 1. Dizajn eksperimenta

\begin{tabular}{|l|c|c|c|c|}
\hline No. & $\begin{array}{c}\text { Koncentracija } \\
\text { boje (mg/l) }\end{array}$ & $\begin{array}{c}\text { Koncentracija } \\
\text { gvožđa (mg/l) }\end{array}$ & $\mathrm{pH}$ & $\begin{array}{c}\text { Koncentracija } \\
\text { vodonik- } \\
\text { peroksida } \\
(\mathrm{mM})\end{array}$ \\
\hline 1 & 180 & 0,75 & 10 & 11 \\
\hline 2 & 20 & 30,375 & 2 & 11 \\
\hline 3 & 180 & 60 & 2 & 11 \\
\hline 4 & 20 & 60 & 10 & 6 \\
\hline 5 & 100 & 60 & 10 & 11 \\
\hline 6 & 20 & 0,75 & 10 & 1 \\
\hline 7 & 20 & 60 & 2 & 1 \\
\hline 8 & 180 & 0,75 & 2 & 6 \\
\hline 9 & 100 & 30,375 & 6 & 6 \\
\hline 10 & 180 & 60 & 6 & 1 \\
\hline 11 & 100 & 0,75 & 2 & 1 \\
\hline 12 & 180 & 30,375 & 10 & 1 \\
\hline 13 & 20 & 0,75 & 6 & 11 \\
\hline 14 & 180 & 0,75 & 10 & 11 \\
\hline 15 & 20 & 30,375 & 2 & 11 \\
\hline
\end{tabular}

\subsection{Karakterizacija tretiranog efluenta}

Fizičko-hemijska karakterizacija efluenta pre i nakon Fenton tretmana je obuhvatila merenje $\mathrm{pH}$ vrednosti, električne provodljivosti, temperature (AD110 Adwa instrument) i mutnoće (Turb 430 IR WTW). Stepen mineralizacije određen je merenjem sadržaja ukupnog organskog ugljenika (eng. total organic carbon - TOC) i hemijske potrošnje kiseonika (HPK). Stepen mineralizacije tretiranog efluenta ustanovljen je primenom jednačina (2 i 3):

$$
\begin{gathered}
\operatorname{TOC}(\%)=\frac{T O C_{0}-T O C}{T O C_{0}} * 100 \\
H P K(\%)=\frac{H P K_{0}-H P K}{H P K_{0}} * 100
\end{gathered}
$$

gde $\mathrm{TOC}_{0}$ i $\mathrm{HPK}_{0}$ predstavljaju sadržaj ukupnog organskog ugljenika, odnosno hemijske potrošnje kiseonika u rastvoru boje pre primenjenog tretmana, a TOC i HPK sadržaj ukupnog organskog ugljenika i hemijske potrošnje kiseonika u rastvoru boje nakon primenjenog tretmana, respektivno [5].

\subsection{Kinetika obezbojavanja realnog efluenta}

Kinetički model koji je korišćen za opisivanje procesa uklanjanja boje iz realnog efluenta pri optimalnim vrednostima koncentracije katalizatora, vodonikperoksida i pH vrednosti rastvora je Behnajady Modirshahla - Ghanbary model (BMG) [6]. Proces je 
zaustavljan u vremenskim periodima od 5 do 180 minuta, nakon čega je merena apsorbanca rastvora. Korišćeni BMG model prikazan je u jednačini (4):

$$
\frac{A_{t}}{A_{0}}=1-\left(\frac{t}{m+b t}\right)
$$

gde $A_{0}$ i $A_{t}$ i predstavljaju početnu apsorbancu boje, odnosno apsorbancu boje u određenom vremenskom periodu $t$, dok su $b$ i $m$ konstante BMG modela koje se odnose na kinetiku reakcije i oksidacioni kapacitet, respektivno.

\section{REZULTATI I DISKUSIJA}

\subsection{Optimizacija Fenton procesa}

$\mathrm{Na}$ efikasnost homogenog Fenton procesa najviše utiče $\mathrm{pH}$ vrednost, koncentracija katalizatora, kao i inicijalna koncentracija boje. Najveća efikasnost homogenog Fenton procesa $(96,86 \%)$ je predložena pri sledećim procesnim uslovima: koncentracija boje $180 \mathrm{mg} / \mathrm{l}$, koncentracija gvožđa 49,43 mg/l, koncentracija $\mathrm{H}_{2} \mathrm{O}_{2} 5,95 \mathrm{~mm}$, $\mathrm{pH}$ vrednost 2 (slika $3 \mathrm{a})$.

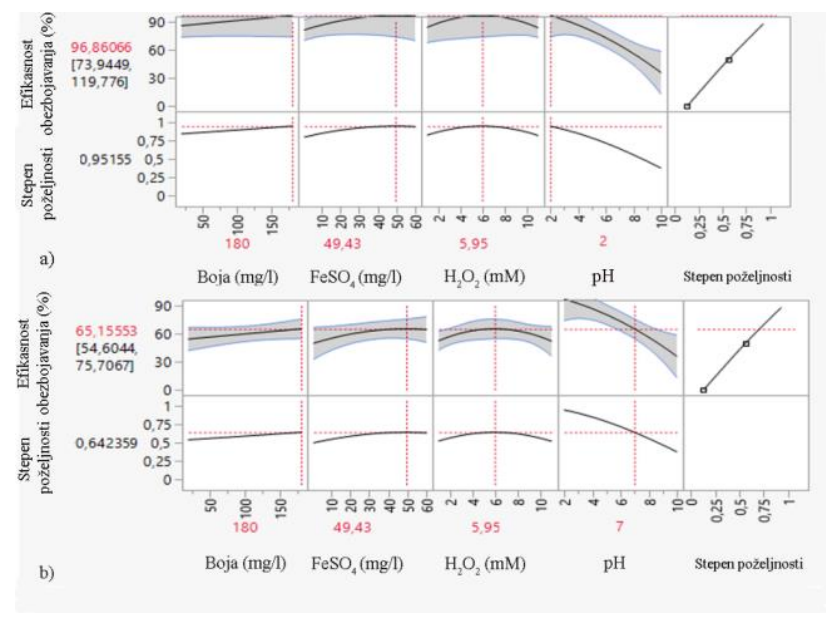

Slika 3. Dijagram optimizacije homogenog Fenton procesa: a) u kiseloj sredini; b) u neutralnoj sredini

$\mathrm{Na}$ slici 3b su prikazani izmenjeni optimalni uslovi, pri čemu je ustanovljeno da povećanje $\mathrm{pH}$ vrednosti malo smanjuje efikasnost obezbojavanja sintetičkog rastvora žute boje. Varijacijom $\mathrm{pH}$ vrednosti efikasnost homogenog Fenton procesa je smanjena na $80,41 \%$, $73,21 \%$ i $65,15 \%$ pri pH 5, 6 i 7, respektivno. Iako niže, ove vrednosti efikasnosti su svakako povoljnije sa aspekta odvijanja tretmana za zaštitu životne sredine, budući da je potreba za održavanjem operativne $\mathrm{pH}$ vrednosti unutar uskog opsega $(2,8$ - 3,5) ključno ograničenje primene homogene Fenton oksidacije. Međutim, kada su eksperimenti praktično sprovedeni, oni su rezultirali stvaranjem velike količine mulja u vidu hidroksida gvožđa, što zahteva primenu dodatnog tretmana u cilju njegovog odvajanja i sanacije, a to sa druge strane povećava troškove tretmana.

\subsection{Tretman i karakterizacija realnog efluenta žute bo-} je pri optimalnim uslovima homogenog Fenton procesa

Uzorak realnog efluenta obojen žutom bojom je podvrgnut homogenom Fenton tretmanu pri ustanovljenim optimalnim vrednostima procesnih parametara. Na slici 4 prikazana je postignuta efikasnost obezbojavanja u vre- menskom trajanju reakcije od 180 minuta. Najveća efikasnost obezbojavanja od 78,80\% postignuta je u 60 . minutu reakcije čime je potvrđena visoka katalitička aktivnost katalizatora gvožđe (II)-sulfata.

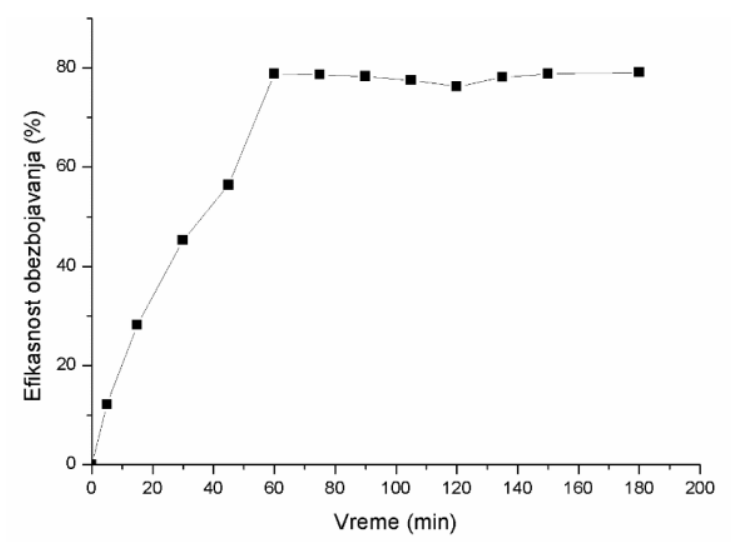

Slika 4. Efikasnost obezbojavanja realnog efluenta žute boje primenom optimizovanog homogenog Fenton procesa

Na slici 5 je prikazan UV/VIS spektar realnog efluenta pre i nakon sprovedenog tretmana. Kod realnog efluenta se uočava izražena apsorpciona traka u vidljivoj oblasti, na talasnoj dužini od $437 \mathrm{~nm}$, koja potiče od -N=N- grupe u hromofori žute grafičke boje. Nakon sprovedenog Fenton tretmana intenzitet pika je znatno smanjen, što odgovara razaranju azo veze i degradaciji žute grafičke boje.

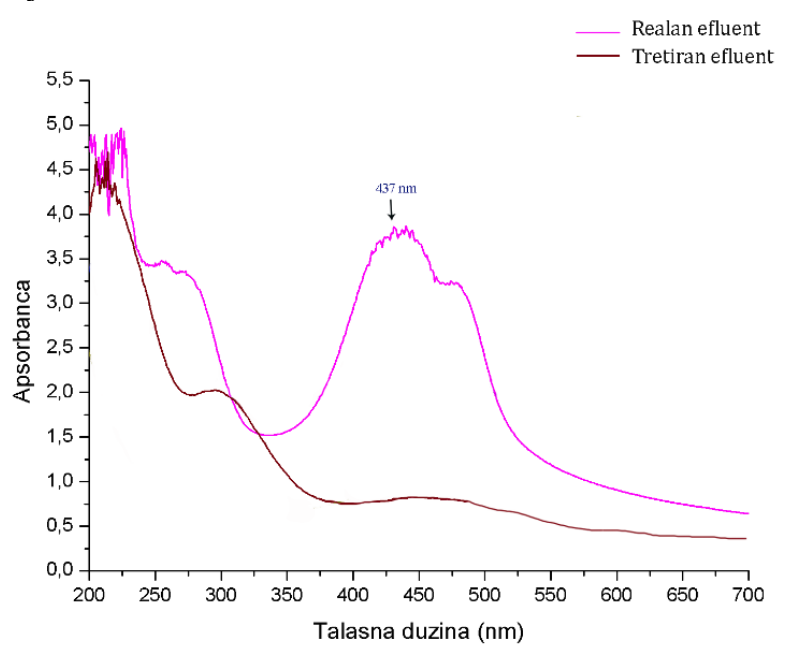

Slika 5. UV/VIS spektar realnog i tretiranog efluenta pri optimizovanim procesnim uslovima primenjenog Fenton tretmana

Određivanjem osnovnih fizičko-hemijskih parametara izvršena je karakterizacija tretiranog efluenta. Rezultati fizičko-hemijske karakterizacije prikazani su u tabeli 2.

Uočeno je da se nakon sprovedenog tretmana povećava provodljivost, a to ukazuje na formiranje brojnih produkata degradacije i oslobađanje određenih neorganskih jona. Takođe je uočeno i smanjenje mutnoće rastvora, a postignut je i značajan stepen uklanjanja TOC i HPK primenom $\mathrm{FeSO}_{4}$ - indukovanog Fenton procesa. S obzirom da je redukcija TOC vrednosti posledica fragmentacije visoko-kompleksnih struktura molekula 
boje na prostije fragmente, a smanjenje HPK vrednosti mineralizacije tretiranog efluenta i grafičke boje, pretpostavlja se da je primenom Fenton tretmana došlo do degradacije molekula boje i formiranja velikog broja prostijih alifatičnih i aromatičnih intermedijera [5].

Tabela 2. Fizičko-hemijska karakterizacija realnog efluenta žute boje pre i nakon tretmana

\begin{tabular}{|l|c|c|}
\hline Parametar & $\begin{array}{c}\text { Realan } \\
\text { efluent }\end{array}$ & $\begin{array}{c}\text { Tretiran realan } \\
\text { efluent }\end{array}$ \\
\hline $\mathrm{pH}$ & 7,60 & 2,03 \\
\hline $\begin{array}{l}\text { Provodljivost } \\
(\mu \mathrm{S} / \mathrm{cm})\end{array}$ & 585 & 718 \\
\hline Temperatura $\left({ }^{\circ} \mathrm{C}\right)$ & 20,60 & 22,30 \\
\hline Mutnoća $(\mathrm{NTU})$ & 154 & 94,1 \\
\hline TOC $(\mathrm{mgC} / \mathrm{l})$ & 101,55 & 21,1 \\
\hline HPK $\left(\mathrm{mg} \mathrm{O}_{2} / \mathrm{l}\right)$ & 326,41 & 132,29 \\
\hline
\end{tabular}

Rezultati ispitivanja kinetike obezbojavanja realnog efluenta primenom homogenog Fenton procesa prikazani su na slici 6.

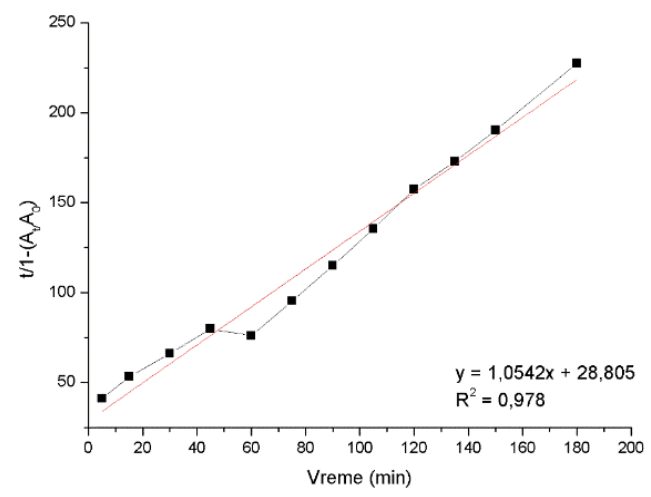

Slika 6. Kinetika obezbojavanja realnog efluenta obojenog žutom bojom pri optimalnim uslovima

Niske vrednosti parametra $1 / \mathrm{m}$ ukazuju da je inicijalna brzina reakcije veoma niska, iz čega sledi da efikasno uklanjanje žute boje iz realnog efluenta zahteva duže reakciono vreme za postizanje visoke efikasnosti.

\section{ZAKLJUČAK}

Rezultati istraživačkog rada ukazuju na činjenicu da efikasnost primenjenog tretmana zavisi od više procesnih parametara, kao što su inicijalna koncentracija boje, koncentracija katalizatora i vodonik-peroksida ali i $\mathrm{pH}$ vrednost. Dizajn i optimizacija eskperimenta su izvršeni primenom statističke metode definitive screening design.

$\mathrm{Na}$ osnovu rezultata statističke obrade podataka zaključuje se da je homogen Fenton proces optimizovan u uskom opsegu pH 2 - 3, sa maksimalnom efikasnošću obezbojavanja sintetičkog rastvora boje od $97 \%$. Nešto niža, ali ne i zanemarljiva efikasnost obezbojavanja sintetičkog rastvora boje je ustanovljena u neutralnoj sredini pri $\mathrm{pH}$ 7. Ipak, homogen Fenton proces sproveden pri neutralnoj $\mathrm{pH}$ vrednosti se odlikuje generisanjem određene količine mulja, što predstavlja nedostatak ove vrste procesa, jer zahteva dodatni koraka u tretmanu ispitivanih efluenata, kako bi se nastali mulj uklonio.
Homogen Fenton tretman rezultovao je sa $78 \%$ efikasnosti u eksperimentu sa realnim efluentom generisanim nakon procesa flekso štampe. Fizičko-hemijska karakterizacija efluenta je rezultovala smanjenjem hemijske potrošnje kiseonika i sadržaja ukupnog organskog ugljenika što ukazuje na određen stepen mineralizacije boje.

Povećana provodljivost realnog efluenta nakon primenjenog tretmana ukazuje na formiranje brojnih produkata degradacije i oslobađanje određenih neorganskih jona koji mogu da potiču iz samog molekula boje.

\section{LITERATURA}

[1] N. Ertugay, F. Acar, "Removal of COD and color from Direct Blue 71 azo dye wastewater by Fenton's oxidation: Kinetic study", Arab. J. Chem., Vol. 10, pp. 1158-1163, February 2017.

[2] Y. Chen, L. Feng, H. Li, Y. Wang, G. Chen, Q. Zhang, "Biodegradation and detoxification of Direct Black $\mathrm{G}$ textile dye by a newly isolated thermophilic microflora", Bioresource Technol., Vol. 250, pp. 650-657, February 2018.

[3] V. Kecić, Đ. Kerkez, M. Prica, O. Lužanin, M. Bečelić-Tomin, D. Tomašević Pilipović, B. Dalamcija, "Optimization of azo printing dye removal with oak leaves-nZVI/ $\mathrm{H}_{2} \mathrm{O}_{2}$ system", $J$. Clean. Prod. Vol. 202, pp. 65-80, November 2018.

[4] C. Felix, A. Ubando, C. Madrazo, S. Sutanto, P. Tran-Nguyen, A. Go, Y. Ju, A. Culaba, J. Chang, W. Chen, "Investigation of direct biodiesel production from wet microalgae using definitive screening design", 10th International Conference on Applied Energy (ICAE2019) Hong Kong, China. 2019.

[5] V. Gvoić, "Ispitivanje mogućnosti primene Fentonprocesa u tretmanu obojenih otpadnih voda grafičke industrije", doktorska disertacija, Univerzitet u Novom Sadu, Prirodno-matematički fakultet, Novi Sad, pp. 1-189, September 2019.

[6] M. Behnajady, N. Modirshahla, F. Ghanbary, "A kinetic model for the decolorization of C.I. Acid Yellow 23 by Fenton process", J. Hazard. matter., Vol. 148, pp. 98-102, September 2007.

\section{Kratka biografija:}

Katarina Novaković je rođena u Užicu 1989. godine. Diplomski rad na Fakultetu tehničkih nauka iz oblasti Grafičko inženjerstvo i dizajn odbranila je 2012. godine.

Miljana Prica je obrazovanje do doktora nauka stekla na Prirodno-matematičkom fakultetu u Novom Sadu. U zvanju vanrednog profesora je od 2014. godine.

Vesna Gvoić je obrazovanje do doktora nauka stekla na Prirodno-matematičkom fakultetu u Novom Sadu. U zvanju asistenta je od 2014. godine. 